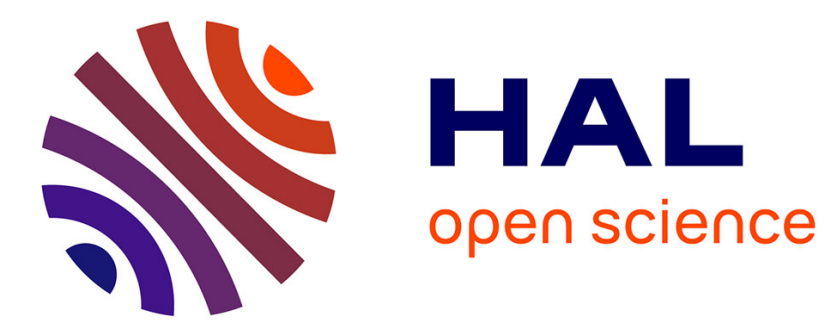

\title{
Investigating the Impact of Visual Representations during Ideation: Towards Immersive eXperience Design
}

Marc Pallot, Laurent Dupont, Sylvain Fleury, Gina Araque-Tellez, Simon

Richir

\section{- To cite this version:}

Marc Pallot, Laurent Dupont, Sylvain Fleury, Gina Araque-Tellez, Simon Richir. Investigating the Impact of Visual Representations during Ideation: Towards Immersive eXperience Design. 2021 IEEE International Conference on Engineering, Technology and Innovation (ICE/ITMC), Jun 2021, Cardiff, United Kingdom. pp.1-8, 10.1109/ICE/ITMC52061.2021.9570244 · hal-03425853

\section{HAL Id: hal-03425853 https://hal.science/hal-03425853}

Submitted on 11 Nov 2021

HAL is a multi-disciplinary open access archive for the deposit and dissemination of scientific research documents, whether they are published or not. The documents may come from teaching and research institutions in France or abroad, or from public or private research centers.
L'archive ouverte pluridisciplinaire HAL, est destinée au dépôt et à la diffusion de documents scientifiques de niveau recherche, publiés ou non, émanant des établissements d'enseignement et de recherche français ou étrangers, des laboratoires publics ou privés. 


\section{Investigating the Impact of Visual Representations during Ideation: Towards Immersive eXperience Design}

\author{
Marc Pallot \\ Arts \& Metiers Institute of Technology \\ LAMPA, HESAM University \\ F-53810 Change, France \\ marc.pallot@ensam.eu
}

\author{
Laurent Dupont \\ Université de Lorraine \\ ERPI \\ F-54000 Nancy, France \\ 1.dupont@univ-lorraine.fr
}

Simon Richir

Arts \& Metiers Institute of Technology

LAMPA, HESAM University

F-53810 Change, France

simon.richir@ensam.eu

\author{
Sylvain Fleury \\ Arts \& Metiers Institute of Technology \\ LAMPA, HESAM University \\ F-53810 Change, France \\ sylvain.fleury@ensam.eu
}

\author{
ina Araque-Tellez \\ ERPI \\ F-54000 Nancy, France \\ giluarte@gmail.com
}

\begin{abstract}
While there is a plethora of publications devoted to the benefits of visualization; its drawbacks, apparently, did not receive the same attention. Nonetheless, a list of potential drawbacks exists in the current body of knowledge, which, unfortunately, do not directly address the facilitation of ideas generation by different design stakeholders, including users. Beside introducing the longer-term goal of a series of planned studies, this paper presents a first empirical study for setting the baseground on immersiveness. The results show that the choice of a visual representation type must be made wisely as it has an impact on the way participants imagine a facility space and its furnishing layout. They also unveil that, for the same facility space, the layout suggested by the participants is likely to be different depending on whether they visualize a top, perspective or sectional view, or even an inspirational photo of the space.
\end{abstract}

Keywords-immersive technologies, creativity, visual representation, immersion intensity

\section{INTRODUCTION}

The purpose of this investigation is to find out the eventual impact of visual representations in expressing ideas of a space usage and corresponding furnishing layout. This investigation belongs to a series of study dedicated to understanding the impact of Immersive technologies on individuals having to generate ideas of facility space and their furnishing. These individuals are in fact stakeholders, including future occupants of these future facilities. This initial empirical study is intended to set the baseground from which different Immersive eXperience Design (IXD) environments could be compared in terms of both potential benefits and eventual drawbacks. The context of this study is a rehabilitation and refurbishment project of an old disaffected building. Different stakeholders were involved for discussing ideas of rehabilitation through the allocation of facility spaces to different local organizations and future occupants operating various artistic and innovation activities.

Bresciani and Eppler provided in 2015 an overview of the common pitfalls and potential drawbacks of visual representations in design [1]. Through a multidisciplinary literature review, they identified a list of potential drawbacks that unfortunately, do not directly address the facilitation of ideas generation by different design stakeholders, including users. This paper presents an initial study focusing on the lowest possible degree of interaction, immersion, technology and cost through the use of drawings or pictures/photos as visual representations; they could be displayed either on a low-cost screen or simply printed on an A4 sheet. Indeed, it constitutes also the simplest design environment affordable to almost everyone, including future occupants. At this stage, participants were not asked to sketch their ideas but rather explain vocally their ideas in terms of both space allocation and corresponding furnishing when looking at each of the four different visual representation forms: (a) top-view; (b) sectional-view; (c) perspective view; (d) inspirational photo.

The up-coming studies in this series are planned to progressively bring onboard of experiments different immersive technologies like large or holographic screens as well as eXtended Reality (XR) technologies like Virtual Reality (VR), Augmented Reality (AR) or Mixed Reality (MR). These studies are targeted to progressively explore above-mentioned various high-tech devices and equipment, delivering different degree of visualization and interaction, in comparing the resulting Immersive eXperience (IX) and generated ideas in terms of: (i) quantity; (ii) variability; (iii) adequation; (iv) innovativeness.

These exploratory studies are intended to address both individual and collective IX. For example: (a) regarding the lowest IX degree in terms of used technology, an individual simply visualize a facility space from an extremely low-cost and low-tech printed drawing with no interaction opportunity as reported in this study; (b) as for the highest IX degree, an individual could be wearing a high-tech Head-MountedDisplay (HMD) for a 3D visualization exhibiting a highest interaction capacity with digitized environment and objects. Indeed, the ability to generate a mind representation of furnishing a specific space from a printed drawing is not in everyone capacity. Hence, it is assumed that immersive technologies would bring a more realistic $3 \mathrm{D}$ view facilitating sensemaking and common understanding among stakeholders about a particular context, situation and expressed ideas [2].

\section{EXISTING TheORIES AND PREVIOUS WORK}

The above-mentioned series of study takes place in the business sector of rooms furnishing within public, 
professional or private building spaces. These studies will reuse and extend our previous work on Immersive Virtual Environment (IVE) and Immersive Collaborative Environment (ICE) [3, 4, 5], including UX [6, 7, 8], Fuzzy Front-End (FFE) model $[9,10]$ and IX [11].

One of these previous studies was carried out on the appropriateness of immersive technologies to supporting cocreation among different stakeholders for redefining accident-prone areas between pedestrians and vehicles in a city [4]. The Lorraine Fab Living Lab ${ }^{\circledR}$ (LF2L), the Équipe de Recherche sur les Processus Innovatifs (ERPI) and Ecole Nationale Supérieure en Génie des Systèmes et de l'Innovation (ENSGSI) platform for prospective assessment of innovative usages and innovation acceptability regularly experiment "low cost" ICE platforms supporting front end innovation development since 2014 [4, 12] (Fig. 1).

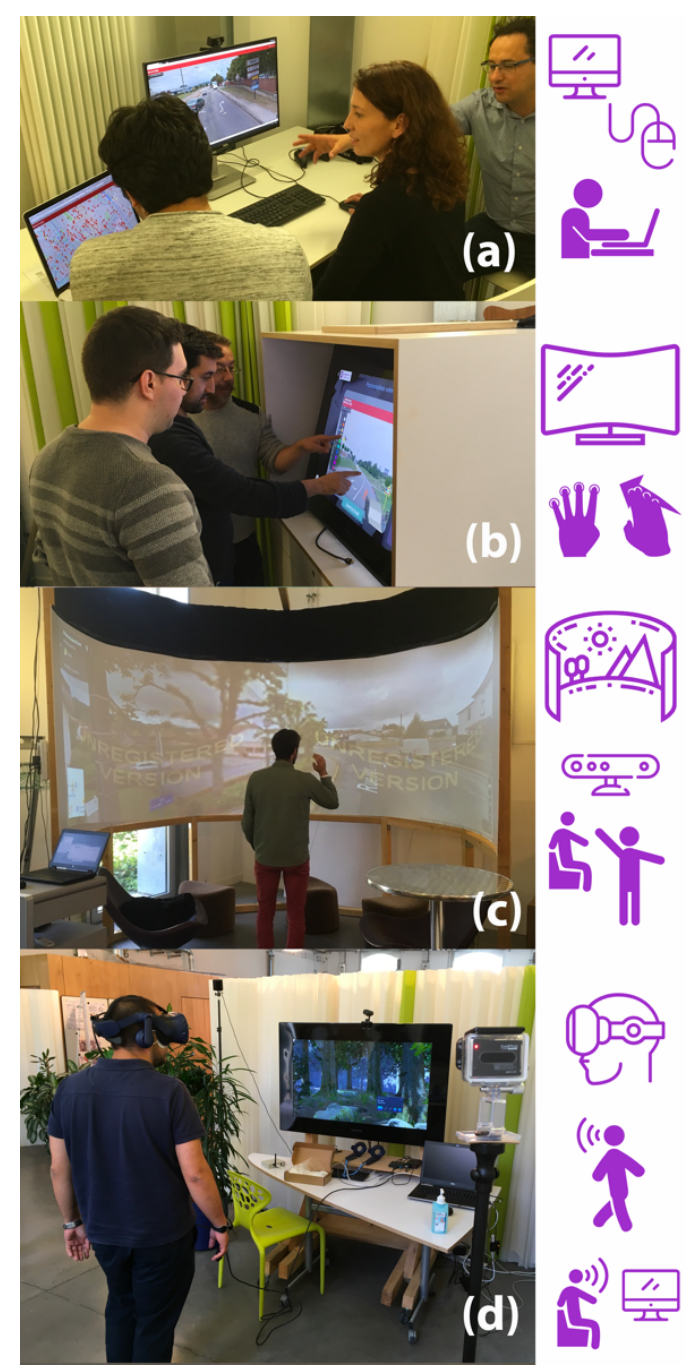

Fig. 1. Pictures of LF2L showing the "low-cost" immersive technologies (Pictures and video are available online at: https://flic.kr/p/U114Zu.)

According to our experience and previous Living Lab (LL) projects involving various stakeholders or communities in a collaborative approach [13, 14], we learnt that it is necessary to propose different levels of sophistication of immersive platforms. Indeed, LL participants do not necessarily share the same backgrounds, knowledge and motivations.

Including the largest number of stakeholders in a collaborative approach supported by an immersive platform, necessitate to consider their different abilities to cope with these new technologies. For example, an experiment conducted during a co-creation workshop of four different ICE platforms (Fig. 1): (a) a multi-screen visualization platform; (b) collaborative interfaces on Multitouch Tables platform; (c) an original collective user experience inside an immersive bubble platform; (d) an HMD-based ICE platform including a control screen for the participants not wearing an HMD. While this case study has confirmed the positive impact of the use of ICE platforms on sensemaking and trustbuilding, the facilitation of reaching a common understanding depending on the type of each ICE platform was not systematically confirmed; as well as for facilitating the co-creation of new knowledge.

A previous publication [15] presents the technical descriptions of ICE platforms (b \& c) and how they work in a complementary manner in the LF2L. These different ICE platforms, through the use of different immersive technologies, deliver different degree of immersiveness; hence, absorption causal effect and level of stakeholders' engagement towards the facilitation of sensemaking and trust-building, reaching a common understanding and cocreation of new knowledge.

In the same vein, another empirical study was dedicated to the impact of immersive technologies on service prototyping [16]. Beside studying the immersiveness impact on ideation, sensemaking and common understanding $[3,4]$, our goal is now to reach a better understanding on the articulation of the phenomena related to immersion, such as: absorption, engagement, flow and presence.

\section{A. User Driven Innovation}

Engaging users in New Product Development (NPD) is not something new as the 'lead user' approach described in 1986, was meant for specifying needs and requirements with the help of users [17]. Later on, it was also demonstrated that users could be a good source of innovative ideas [18]. In 2009, the Living Lab approach was described as a kind of open innovation ecosystem where users/citizens co-create value [19]. User-Centered Design (UCD) methods [20, 21] shifted the priority towards co-creating value with users in order to ensure a higher rate of technology acceptance and product/service adoption [22], which is the ultimate goal of innovation.

UCD methods are also intended to reduce the gap between perceived needs and real needs. Furthermore, Curley and Salmelin [23] recently mentioned that the concepts of 'User-Driven Innovation' (UDI) [24] and 'User Co-Creation' (UCC) $[21,24,25]$ are vital ingredients of the Open Innovation 2.0 paradigm: "User- driven innovation is a crucial part of the OI2 paradigm and is also a key lever for adoption because users co-create solutions that meet their needs". Recently, inspired by the "Do-It-Yourself" (DIY) and "Do-It-Together" (DIT) movements [26], a new DIT approach, enhanced by the impact of social media from cocreation to NPD and manufacturing, emerges as a concrete application of UDI [27].

\section{B. User Centered Design}

For several decades, User-Centered Design (UCD) has broadly disseminated in the field of information technology, which has moved from a techno-centric to an increasingly anthropocentric approach [28]. UCD is a design approach focusing on the expectations, characteristics and needs of 
users, which requires the involvement of potential users as early as possible in the design process [29].

Although it was first developed for software projects, UCD is nowadays pretty popular within different sectors, such as: public services [30], health [31] or building [32]. Participatory design, or co-design, is a form of UCD that emphasizes the active role of users in the design process. While UCD ensures a good fit with expectations and needs, participatory design additionally promotes user engagement in projects and adherence to its outcome [33].

\section{C. eXperience Design}

Other well-known forms of UCD are contextual design and experience design. In late Spring 2018, a study surveying 6,000 consumers in the US, UK and China show that firms designing experiences instead of product features have 200\% greater recommendations and $25 \%$ more customer loyalty [ 34 survey]. However, it requires multiple stakeholders, especially users, to be engaged along the iterative $\mathrm{XD}$ process (Fig. 2) for: (1) co-creating innovative ideas; (2) exploring alternative usage scenarios; (3) experimenting how alternative solutions could properly support usage scenarios; (4) evaluating usage scenarios through UX quality measurement $[6,21,22]$.

These four activities (Fig. 2) are intended to better support the identification, implementation and evaluation of attainable value elements, for example: usefulness, efficiency, reliability, affordability, usability, trustability, empathy, and enjoyability. These value elements are turned into UX properties and grouped within UX facets.

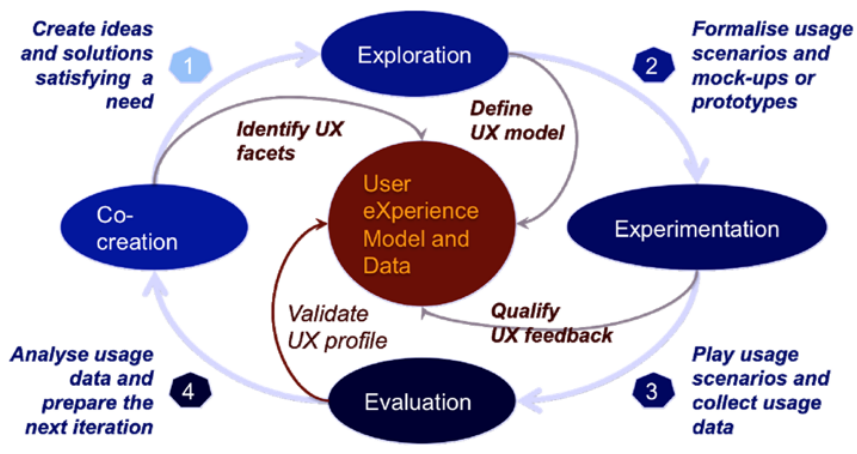

Fig. 2. Iterative eXperience Design (XD) process [6, 21, 22]

This brings us to the central premise and core rationale of our validated UX-based adoption model relying on the main assumption that the higher the measured score of each UX facet, the more likely users would adopt the corresponding innovative solution $[22,35]$.

\section{User eXperience}

According to Pallot and Pawar [6], User eXperience (UX) is a multidimensional and multifaceted concept linked to the phenomenon of rapidly evolving human perception of usage experiences. In fact, the experience of using whatever objects or systems constantly evolves through a learning experience life-cycle from being a beginner up to becoming an expert. Furthermore, UX evolves also along the design process starting from anticipated use, progressing with virtual and physical mockup or prototype usage and ending up with [22, 36]. This is known as the UX life-cycle [37]. Pallot and Pawar [6] argue that UX is so complex that most of the available empirical studies investigate only one fraction of it; UX is often observed from the single business dimension perspective through the technological facet, which includes constructs like utility and usability (ergonomic quality); sometimes they include the economical facet with constructs like pleasantness (hedonic quality) and satisfaction. More recently, Tcha-Tokey et al. [38] made an attempt for validating an UX in IVE conceptual model whose results show the impact of experience consequence on Flow and Emotion while Presence and Technology Adoption is impacted by Flow; in the same vein, Engagement impact on Presence and Immersion but no correlation between Presence and Immersion in contrast with another study [39].

\section{E. The complexity of the phenomenon of Immersion}

The Oxford dictionary tells us that: "immersion represents the state of being: (i) put under the surface of a liquid; (ii) involved deeply or absorbed in a book, thought, work, one's business". From the same dictionary, absorbed means: "use up much of the attention, interest or time of". Therefore, one could reasonably argue that absorption represents a causal effect of immersion. This is confirmed by the work of Nordin et al. [40], characterizing this absorption phenomenon as Real-World Dissociation (RWD). According to Pallot and Richir [41], immersion is sustained by three types of human activity (physical, cognitive or emotional) where a person is fully absorbed: (a) playing sport or exergame, known as being a tactical/sensory-motoric immersion; (b) solving an issue (mental challenge, chess game), known as being a strategic/cognitive immersion; (c) listening to, reading or watching a captivating story, known as being a narrative/emotional immersion [42, 43]. It often appears that once participants are captivated by a story and feeling engrossed into a character experience, then, occurs an emotional transfer leading to the phenomenon of immersion; exhibiting the fact that other needs become negligible and an induced RWD effect.

Immersive technologies are considered as enabling the perception of being bodily there while in a mediated immersive environment allowing interaction and communication; where one or more of the five senses are engaged [15]. Immersion could happen in physical, cognitive or collective form [7]. From this perspective, Staffan and Holopainen [43] argue that spatial immersion reflects the degree to which a simulation participant perceives the virtual environment as a real one; implying the feeling of presence [44]. Cummings and Bailenson [45] argue that the highest quality of immersion of the IVE, the more likely users will feel present in the IVE and will perceived the mediated environment as a plausible space in which they feel located. Based on the definition of presence from Wirth et al. [44] Cummings and Bailenson came to the conclusion that the concept of presence is a two-dimensional construct comprising the user sense of self-location and perceived opportunities to interact with the IVE [45].

These types of immersion make one's brain so busy that everything else around simply disappears. A pretty good way to measure the deepness to which a person is absorbed is to observe whether the notion of time disappears as well as the whole external world. To make it short, one could argue that a $360^{\circ} \mathrm{VR}$ immersion bubble operates like a mind-blowing teleportation, instantaneously transporting a user in an existing remote place or a different world that is persistent enough to become another reality, even if it is a virtual one. 
Pallot and Pawar [6] argue that immersive technologies allow a more accurate representation of stakeholders' time and space experience while providing a better usability testing of usage scenarios in an affordable and flexible manner. Hence, they foresee immersive technologies as an opportunity to facilitating sensemaking and common understanding [2] among project stakeholders simply because they bring a more realistic $3 \mathrm{D}$ visual representation about an innovative idea, its related concepts and usage scenarios. This would imply far less risks of misinterpretation during the FFE stage and co-design of the Immersive eXperience.

\section{$F$. Immersive eXperience}

The immersiveness of a specific environment is characterized by its particular UX as it was demonstrated through the use of a service prototype UX research model [11]. This model was statistically validated [16]. Therefore, it demonstrated that IX is a particular type of experience or UX facet having its own UX properties allowing to evaluate its degree of experience satisfaction. This is linked to our main research motivation in this series of study, investigating whether an IX relies mainly on the pictorial experience that is a typical experience associated with seeing-in pictures [46], with a certain degree of photo-realism; hence, justifying this present investigation on the impact of different visual representations.

\section{G. Immersive eXperience Design}

We foresee Immersive eXperience Design (IXD) as a specific type of XD allowing project stakeholders to be immersed, at some degree, in an IVE or ICE even if only one of them master the implementation and use of XR technologies. We also assume that the most prominent interest of IX, through its 3D visual representation, resides in its dual capacity to facilitating sensemaking and common understanding while eventually limiting the degree of imagination. There are already examples of IXD application in the built environment: (a) IVE engaging future occupants in the building design process in delivering a sense of presence while integrating pre-construction mock-ups and BIM models. This app allows evaluating alternative design options in the building model in a timely and cost-efficient approach [47]; (b) IVE for evaluating future occupants' lighting preferences through virtual scenes with the controlling of the blinds and artificial lights in the virtual environment [48].

\section{H. Visual Representation}

In the context of this study, project stakeholders use a visual representation to facilitate the sensemaking and a common understanding that are essential enablers of an effective and efficient collaborative work [2]. According to Broberg et al. [49], this visual representation can take many forms, from paper sketches to more elaborated digital forms up to VR sketches, to facilitate the designer's mind representation to work with, and to create a common understanding among project stakeholders including future occupants.

The construction industry has embraced the use of Building Information Modeling to communicate about projects between colleagues and partners involved, but also with users (future occupants). A large body of research has established that in a user-centered design approach to a building or its layout, immersive visualization can improve performance on several criteria, including engagement and spatial representation $[50,51]$. Shiratuddin and co-authors [52] have already compared the effectiveness of visualization in this context through diverse 3D technologies like a Cave Automated Virtual Environment (CAVE), a HMD, a large hemispheric display and a conventional display.

The results indicate that on almost all criteria, the CAVE performs best. The HMD and the hemispherical display are inferior to the CAVE, but overall, more effective than a conventional screen display when they are combined with the 3D adapted model. It should be noted that these are very specific equipment and immersing future users in these environments, especially the CAVE, can be pretty costly in terms of buying the technology and spent time on the preparation. This can therefore be a major obstacle to the use of these immersive technologies in a user-centered design approach in the furnishing sector. This observation leads to investigate much cheaper visual supports like different types of drawings or images, namely: realistic view, simplified view, schematic view, inspiring view. These drawings or images could be displayed on any basic screen or printed on a sheet of paper.

Tavanti and Lind [53] argue, in their study on data visualization, that $3 \mathrm{D}$ representation projected onto a $2 \mathrm{D}$ surface allows more data to be shown than in a front view, and leads the user to more easily get the full picture of the presented data. The hypotheses of the present study are that by showing different types of visual representation of a facility space to future users, they generate different ideas of usage mode and different ideas of furnishing.

\section{METHODOLOGY}

\section{A. Context and Purpose}

Although many studies unveiled the effectiveness of immersive technologies in promoting participant engagement and project visualization $[50,51]$, a CAVE equipment is not so common within industrial firms, especially SMEs, due to its cost. To enable the majority of designers, particularly in the building and furniture sectors, to adopt a more usercentered and participatory approach, it is necessary to compare the impact of using low-tech and high-tech media. This study focuses on the use of low-tech means like printed or displayed drawings and photos. This investigation was conducted as part of a project intended to refurbish historic buildings for accommodating various artistic and innovation activities. The purpose of this study is to provide some evidence about the impact that different types of visual representation can play in engaging stakeholders, especially future occupants, in expressing ideas of usage and furnishing layout for a facility space.

The old buildings of the Rives-de-Meurthe district in Nancy, France, are seeing a new face, with nearly 4,600 m2 restructured into a Cultural and Creative Nursery. This place is intended to be an open space allowing the connection of future occupants, such as artists and creatives, with the inhabitants of the city and companies. Four large buildings (Fig. 3) are expected to provide a friendly and multidisciplinary meeting place between culture and innovation; open to experimentation and intended to operate as a creative laboratory for the city.

Initiated by the city of Nancy, this regional development project for cultural and economic development led to the 
creation of the OK3 association to co-develop, manage and animate this site. The board of directors of this association is made up of 20 actors from the Rives de Meurthe sector and multidisciplinary artists, managers of the animation of the place and the selection of its first residents; in addition to complete the restoration of the buildings, a local team of architects was commissioned by the city of Nancy to design and manufacture the furniture for these new spaces.

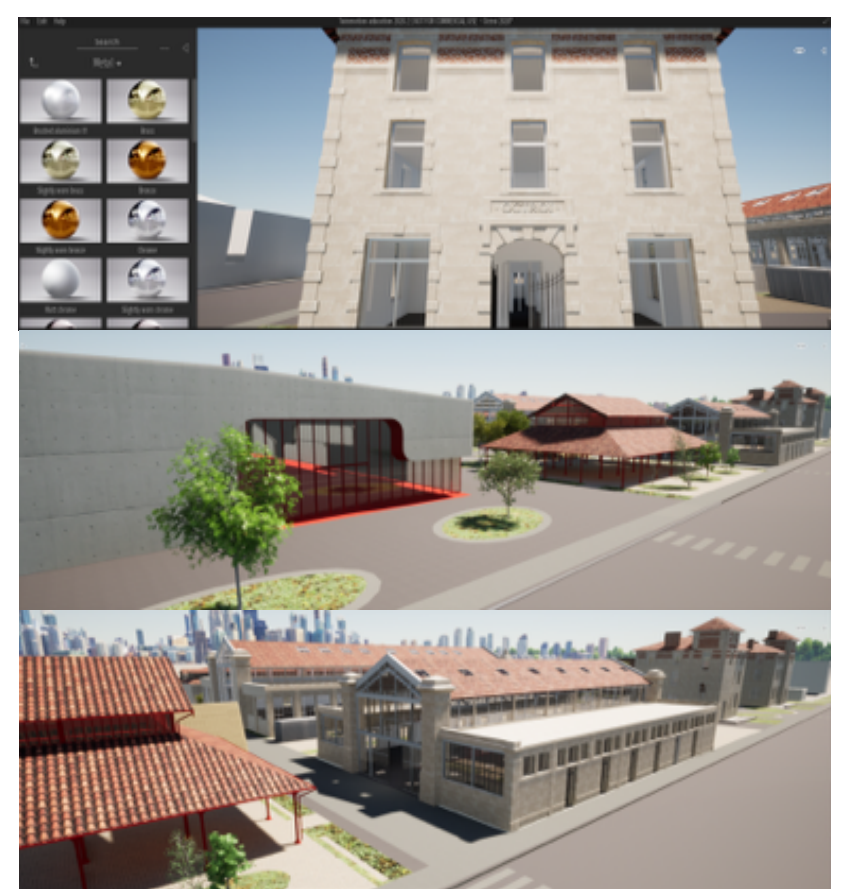

Fig. 3. The digitized OCTROI site

As part of the co-development led by OK3, Laurent Dupont, Secretary General and responsible for the experimentation of the platform for co-design and social manufacturing of the INEDIT project, proposed that the rehabilitation project of the Octroi site become a field of exploration from the co-creation of ideas, through the codesign of spaces and up to the manufacturing of furniture.

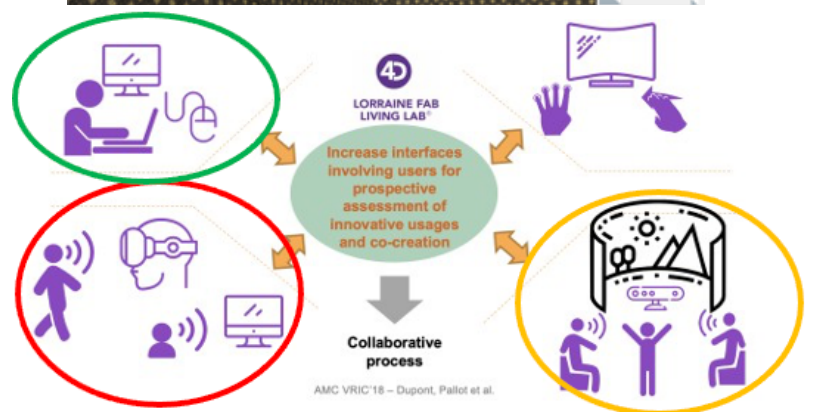

Fig. 4. Immersive and Collaborative Environments [5]

Due to the COVID19 pandemic, a pretest and a remote test dedicated to visual representations on a screen have been developed to be carried out virtually by videoconference. The participant, through the use of a laptop, tablet or smartphone, can view the images on the screen and answer the interviewer's questions. For this study, we only use the screens as symbolized by the green circle (fig. 4).

\section{B. Research Approach, Questions and Hypotheses}

In this empirical study, a deductive approach is applied for answering the research questions and testing the hypotheses.

RQ: To what degree the type of visual representation of a facility space impact the level of creativity of a stakeholder regarding expressed ideas of potential: (1) space usages and (2) furnishing layout and (3) how can this be quantified?

The hypotheses were that depending on the visual representation type shown to a stakeholder during the interview: (H1) expressed ideas of usage of the facility space would be different; (H2) expressed ideas of furnishing layout would be different.

\section{Research Methods}

A qualitative method was selected through the individual semi-structured interview of participants $(n=12)$. Regarding the data analysis, collected qualitative data have been turned into quantitative data. The quantification provides elements allowing comparison of groups, with a clear statistical criterion for determining the "significant" differences from those that are not. Furthermore, the quantitative analysis is intended to reduce the cognitive bias of the human-generated data. The live one-on-one semi-structured interviews were directly recorded into textual feedbacks.

\section{Sample}

A total of 12 project stakeholders, including future occupants that are the potential users of each facility space, among city employees, architects, artists, and designers were interviewed. There were 10 men and 2 women, the oldest was 64 years old while the youngest was 27 years old for an average age of 48 years. Among them, 6 respondents declared that they were used to read drawings; 4 used them time to time and 2 were not familiar at all with reading drawings.

\section{E. Protocol}

Participants were, in a first step, involved in a workshop intended for discussing about future activities (usage spaces) that could be held in the "Octroi" building to be refurbished. For the second step, participants were instructed about the objectives of this study and the data that would be stored in this context.

They had to agree in giving their signature as a free and informed consent regarding their participation to this study. Afterwards, they were shown a drawing of one of the facility spaces in the building to be refurbished. From this drawing, they had to imagine and say out loud for 5 minutes all the possible usage spaces they could envision for this room.

They were then asked to select the most relevant usage space and create its furnishing. Four different types of each room representation (Fig. 5) to the participant: (i) top view representing a simple two-dimensional plan with some simple furniture; (ii) sectional view representing a side view of the room with the same furniture and a character; (iii) view in perspective representing a $3 \mathrm{D}$ view with the furniture and a character; (iv) inspirational photo representing a realistic picture of the space, as it is at the time of this study, and another photo of an original piece of furniture. 


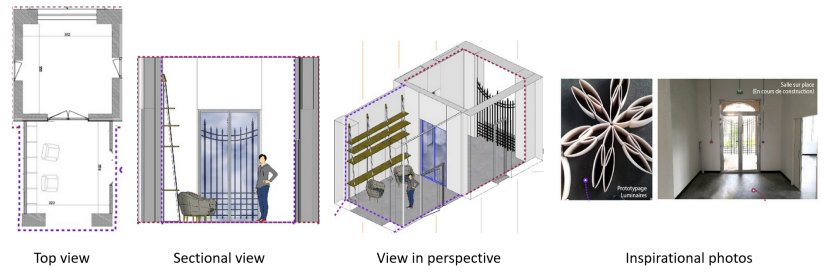

Fig. 5. The four different representation views

Each participant was asked to express ideas for usage space and furnishing layouts 4 times, for 4 different rooms and in different representations. The order in which the representations were presented was counterbalanced with regard to the representation types and the rooms. The choice of positioning some furniture and a character on the representations of the room was intended to give notions of proportion and space.

\section{F. Analysis Methods}

The recorded one-on-one interviews were parsed for: (i) counting the number of expressed words in each respondent's description of usage spaces and furnishing. This is intended to compare respondents' fluency according to the shown representation view; (ii) identifying the category of usage spaces like conviviality space, co-working space, exhibition $\&$ projection space, meeting space, reception space and training space; (iii) identifying the features of the furnishing like modularity, table/desk, decoration, shelving, wardrobe, lighting, socket, acoustics, coffee/water, whiteboard, movable partitions. Based on the identified usage category and furnishing features and the fact that each representation view was executed the same number of times, it was possible to compare the number of occurrences of each usage category and each furnishing feature expressed by the participants.

\section{FINDINGS}

\section{A. Quantitative Analysis}

The means and standard deviations of the number of words in the responses to the question on uses and layout are presented in Fig. 6.

The homogeneity of variance (homoscedasticity) of these data was verified using the variance analysis [54] (Levene, 1960), which revealed to be acceptable for the number of words concerning usages $(\mathrm{F}(5)=1.742, \mathrm{p}=.133)$ and layout $(\mathrm{F}(5)=.754, \mathrm{p}=.585)$.

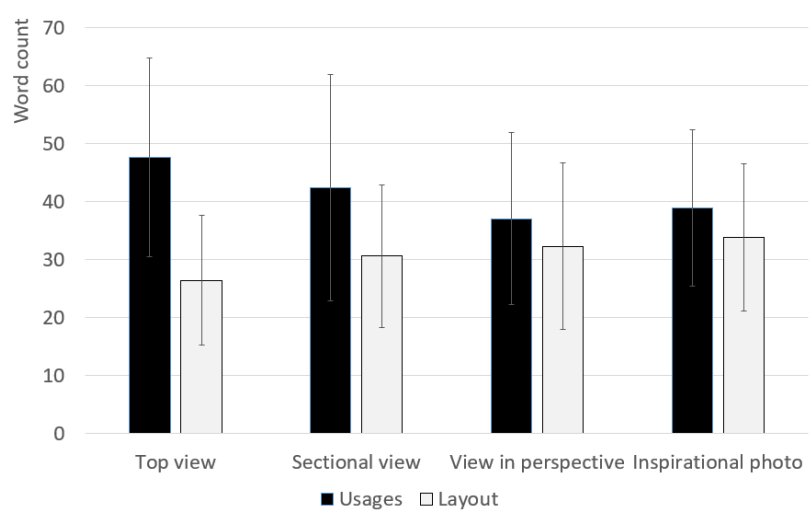

Fig. 6. Average number of words used by respondents in expressing their ideas of usage mode and furnishing feature by representation view
The comparison of the means between the 4 representation types was therefore carried out using variance analysis. It did not reveal any statistically significant difference between the number of words used to describe the ideas of usage, $\mathrm{F}(5)=.657, \mathrm{MSE}=603, \mathrm{p}=.657$. In contrast, the variance analysis revealed a significant difference for the number of words describing the layout ideas, $\mathrm{F}(5)=2.528$, $\mathrm{MSE}=1048.9, \mathrm{p}=.036$. Pairwise comparisons showed that this difference was specifically between the Sectional View and the Inspirational photo $(\mathrm{p}=.048)$. The other differences were not significant $(\mathrm{p}>.05)$.

\section{B. Qualitative Analysis}

The number of proposed usage spaces corresponding to each category according to the four representation types is presented in Fig. 7. The comparison of the representation types was carried out by chi-squared (Chi2) tests [55] (Pearson, 1900). It revealed no significant difference for conviviality $(\mathrm{Chi} 2(4, \mathrm{~N}=12)=58.573, \mathrm{p}=.125)$, co-working office $($ Chi2 $(4, \mathrm{~N}=12)=56.940, \mathrm{p}=.908)$, exhibition \& projection (Chi2(4, N=12) = 37.896, $\mathrm{p}=.739)$, meeting $(\mathrm{Chi} 2(4, \mathrm{~N}=12)=60.518, \mathrm{p}=.416)$, reception $(\mathrm{Chi} 2(4$, $\mathrm{N}=12)=60.231, \mathrm{p}=.705)$ and training $(\mathrm{Chi} 2(4, \mathrm{~N}=12)=$ $39.142, \mathrm{p}=.947)$.

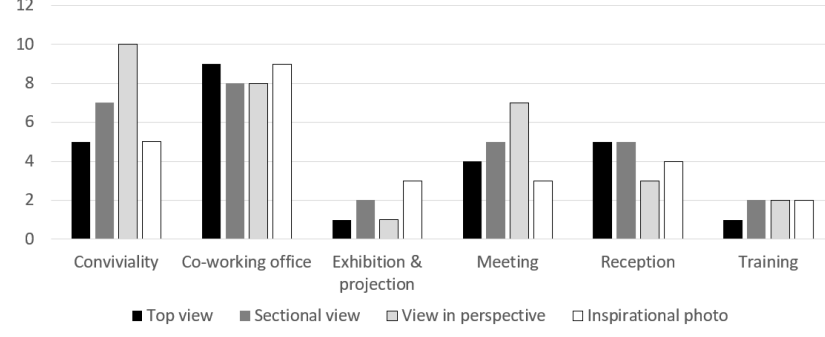

Fig. 7. Number of occurrences for each usage term according to each representation view

Concerning the ideas of furnishing features, the number of occurrences for each layout category in each representation type appears in Fig. 8. The comparison between representation types was carried out by chi-squared tests. It revealed no significant difference for modularity (Chi2(4, $\mathrm{N}=12)=62.012, \mathrm{p}=.657)$, table/desk $(\mathrm{Chi} 2(4, \mathrm{~N}=12)=$ $55.159, \mathrm{p}=.594)$, decoration $($ Chi2 $(4, \mathrm{~N}=12)=49.907, \mathrm{p}=$ $.090)$, shelving $(\mathrm{Chi} 2(4, \mathrm{~N}=12)=58.299, \mathrm{p}=.112)$, wardrobe $(\mathrm{Chi} 2(4, \mathrm{~N}=12)=55.159, \mathrm{p}=.594)$, lighting $(\mathrm{Chi} 2(4, \mathrm{~N}=12)$ $=44.049, \mathrm{p}=.106)$, socket $(\operatorname{Chi} 2(4, \mathrm{~N}=12)=31.194, \mathrm{p}=$ $.290)$, acoustics (Chi2(4, N=12) = 32.440, $\mathrm{p}=$. 444), coffee/water $(\mathrm{Chi} 2(4, \mathrm{~N}=12)=50.697, \mathrm{p}=.913)$, whiteboard $(\mathrm{Chi} 2(4, \mathrm{~N}=12)=13.586, \mathrm{p}=.551)$ and movable partitions $(\mathrm{Chi} 2(4, \mathrm{~N}=12)=30.811, \mathrm{p}=.252)$.

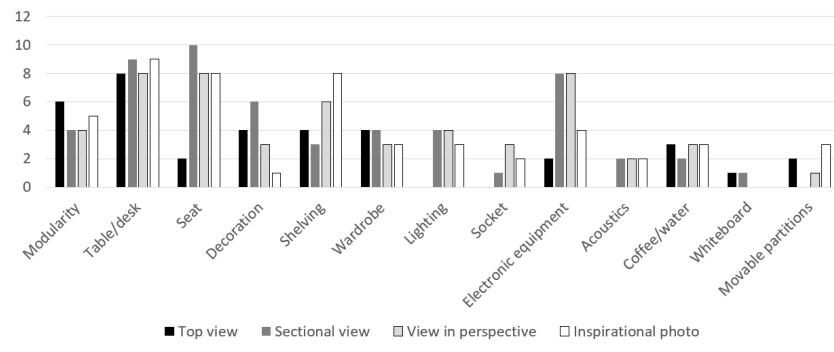

Fig. 8. Number of occurrences for each furnishing term according to each representation view

In contrast, there was a significant difference for seat $(\mathrm{Chi} 2(4, \mathrm{~N}=12)=51.797, \mathrm{p}=.009)$ and electronic equipment 
$($ Chi2 $(4, \mathrm{~N}=12)=56.260, \mathrm{p}=.041)$. It can be seen that respondents tend to mention seats and electronic equipment less in the Top View representation than in the other representation types.

\section{DisCUSSION AND CONCLUSION}

\section{A. Limitations, Reliability and Validity}

This study has the following limitations: (i) it was based on a specific project that has the advantage of being a real case, but with local particular characteristics hindering the generalization of the findings; (ii) the relatively small number of respondents hinders any deeper statistical analysis.

The hypotheses are only partially confirmed by the results of this study. On the one hand, it can be seen that the differences in visual representation types have no significant impact on stakeholders expressing ideas of usage space (H1), either in terms of number of words or in terms of evoked usage space. On the other hand, the visual representation type, in which the furnishing layout (H2) is presented, do make a significant difference both in terms of quantity and variability. Respondents exposed to the Sectional View expressed significantly fewer words than in the Inspirational photo, while respondents exposed to the Top View expressed less words about seats and electronic equipment in their responses ( $\mathrm{H} 2)$.

One may wonder why the difference in visual representation types leads to a difference in the furnishing layout ideas $(\mathrm{H} 2)$, but not in the usage space ideas $(\mathrm{H} 1)$. This could be due to the fact that this study took place after participants had a workshop for discussing their expectations in terms of future activities that could be held in this refurbished building. Therefore, to a certain extent, they already have uncovered ideas about future usage spaces of the different facility spaces planned in this building. Because the question of furnishing layout had not really been addressed during this workshop, this has potentially left participants to be more receptive to the influence of the shown visual representation type.

This study shows that in this approach, the choice of a representation type must be made wisely as it has an impact on the way participants imagine a facility space (RQ1) and its furnishing layout (RQ2). For the same project and the same place, the furnishing layout suggested by the participants is likely to be different $(\mathrm{H} 2)$ depending on whether the designer has shown a top view of the place or a sectional view, for example.

This study also highlights an important point of vigilance in any participatory design process: the temporality of the different co-design actions in the course of the project. In this case, if the usages are not questioned from the outset, there is a risk that they will remain fixed without any possible return. To make precise recommendations on the basis of these results, it seems prudent to imagine iterative approaches in which the visual representations evolve as the ideas of future occupants are enriched and selected.

This initial empirical study requires to be renewed with more participants allowing a deeper statistical analysis for better understanding the impact of each visual representation type. Nonetheless, this study has allowed to set the baseground from which different IXD environments will be compared during up-coming experiments in terms of both potential benefits and eventual drawbacks. While this study constituted the lower degree of technology support, upcoming studies will showcase XR technologies. The next empirical studies will further investigate the phenomena of absorption, immersion, engagement, social-presence and the role pictorial experience (visual representation) as well as their respective impact on FFE, IXD and IX.

\section{ACKNOWLEDGMENT}

This study was partly funded by the European Commission through the INEDIT E.U. innovation project (Grant agreement N 869952). Authors wish to thank the European Commission, all participants of this study, Benjamin Ennesser-Serville (UL-ERPI-ENSGSI-LF2L) and the association OK3 - Octroi Nancy as well as Collectif HOBO, Les Établissements Tourneux, and Caroline Leloup, OBIKA Architecture.

\section{REFERENCES}

[1] S. Bresciani and M.J. Eppler, "The Pitfalls of Visual Representations: A Review and Classification of Common Errors Made While Designing and Interpreting Visualizations," SAGE Open, 2015.

[2] M. Pallot, "Collaborative Distance: Investigating Distance Factors Affecting Collaboration Performance," LAP LAMBERT Academic Publishing, 2012.

[3] M. Pallot, L. Dupont, O. Christmann, S. Richir, B. Vincent, and L. Morel, "ICE Breaking: Disentangling Factors Affecting the Performance of Immersive Co-creation Environments," In Proceedings of VRIC '17 the Virtual Reality International Conference, pp. 1-7, 2017.

[4] L. Dupont, M. Pallot, L. Morel, O. Christmann, V. Boly, and S. Richir, "Exploring Mixed-methods Instruments for Performance Evaluation of Immersive Collaborative Environments," The International Journal of Virtual Reality 17, 2: 1-29, 2017.

[5] L. Dupont, M. Pallot, O. Christmann, and S. Richir, "A Universal Framework for Systemizing the Evaluation of Immersive and Collaborative Performance," In Proceedings of the Virtual Reality International Conference-Laval Virtual, pp. 1-10, April 2018

[6] M. Pallot, and K. Pawar, "A holistic model of user experience for living lab experiential design," In Proceedings of the IEEE International Conference on Engineering, Technology and Innovation (ICE/ITMC), pp. 1-15, June 2012 .

[7] M. Pallot, R. Eynard, B. Poussard, O. Christmann, and S. Richir, "Augmented sport: exploring collective user experience," in The ACM Proceedings of Virtual Reality International Conference, 2013.

[8] R. Eynard, M. Pallot, O. Christmann, and S. Richir, "Impact of Verbal Communication on User Experience in 3D Immersive Virtual Environments," in Proceedings of the 21st ICE/IEEE International Environments," in Proceedings of the 21st ICE/IEEE Internd
Technology Management Conference, Belfast, Ireland, 2015.

[9] A. Lecossier, M. Pallot, P. Crubleau, and S. Richir, "Applicationofthe UX-FFE model for optimizing the performance of the upstream innovation process," in IEEE Proceedings of the 24rd International Conference on Engineering, Technology and Innovation, 2018.

[10] A. Lecossier, M. Pallot, P. Crubleau, and S. Richir, "Towards Radical Innovations in a Mature Company: an Empirical Study on the UX-FFE Model". Journal of Artificial Intelligence for Engineering Design, Analysis and Manufacturing. AI EDAM 33 (2), 172-187, 2018.

[11] A. R. Abdel Razek, C. van Husen, M. Pallot, and S. Richir, "A Proposed Research Framework and Model for Service Prototyping," In 2018 IEEE International Conference on Engineering, Technology and Innovation Proceedings (ICE/ITMC), pp. 1-8, June 2018.

[12] L. Dupont, L. Morel, and P. Lhoste, "Le Lorraine Fab Living Lab: la 4ème dimension de l'innovation," in Actes des sessions du colloque Science \& You, France, pp. 230-235, 2015.

[13] L. Dupont, C. Guidat, L. Morel, and N. Skiba, "The role of mock-ups in the anticipation of the user experience within a living lab: An empirical study," in 2015 IEEE International Conference on Engineering, Technology and Innovation/ International Technology Management Conference (ICE/ITMC), pp. 1-8, 2015.

[14] L. Dupont, V. Gholipour, L. Morel, J.-C. Bignon, and C. Guidat, "From Urban Concept to Urban Engineering: The Contribution of Distributed Collaborative Design to the Management of Urban Projects," J. Urban Des., vol. 17, no. 2, pp. 255-277, May 2012.

[15] L. Dupont, L. Morel, and M. Pallot, "Exploring the Appropriateness of Different Immersive Environments in the Context of an Innovation Process for Smart Cities," In Proceedings of the IEEE Internationa

[16] A. R. Abdel Razek, "Impacts of Immersive Technologies on Service Prototyping: Investigating the performance, experience, and acceptance of different service prototype forms," Doctoral dissertation, HESAM Université, 2020

[17] E. Von Hippel, "Lead users: a source of novel product concepts". Management Science 32, (1986) 791-805

[18] E. Von Hippel, "Democratizing Innovation", MIT Press, Cambridge, MA, 2005 
[19] M. Pallot, "The Living Lab Approach: A User Centered Open Innovation Ecosystem". Webergence Blog 2009 Retrieved January 2011 http://www.cwe-projects.eu/pub/bscw.cgi/715404

[20] M. Pallot, B. Trousse, B. Senach, and D. Scapin, "Living Lab Research Landscape: From User Centered Design and User Experience towards User Co-creation". Proceedings of the Living Lab Summer School, Paris, August 2010

[21] M. Pallot, M. Kalverkamp, S. Vicini, B. Trousse, A. Vilmos, K. Furdik, R. Nikolov, "An Experiential Design Process and Holistic Model of User Experience for Supporting User Co-creation," In Open Innovation Yearbook 2014, Directorate-General for Communications Networks, Content and Technology, Luxembourg: Publications Office of the
European Union, 2014. ISBN 978-92-79-33017-9 doi:10.2759/32049

[22] M. Pallot, K. S. Pawar, P. Krawczyk, M. Topolewski and A. Lecossier "Anticipated User eXperience as a Means to Reveal the Potential Adoption of Innovative Ideas," In Proceedings of the 26th IEEE
Conference on Eng., Techno. and Innov., Cardiff, UK, June 2020.

[23] M. Curley and B. Salmelin, "Open Innovation 2.0: A New Paradigm", OISPG White Paper, 2013.

[24] M. Pallot, "The Living Lab Approach: A User Centered Open Innovation Ecosystem". Webergence Blog 2009 Retrieved January Innovation Ecosystem". Webergence Blog 2009 Retriev

[25] V. Ramaswamy and F. Gouillard, "The Power of Co-Creation: Build it with them to Boost Growth, Productivity, and Profits". New York: Free Press, 2010.

[26] A.L. Hirscher, K Niinimäki, C.M.J. Armstrong, "Social manufacturing in the fashion sector: New value creation through alternative design
strategies?". Journal of cleaner Production 172: pp 4544-4554, 2018 .

[27] M. Pallot, S. Fleury, B. Poussard, S. Richir, "What are the Challenges and Enabling Technologies to Implement the Do-It-Together Approach, its Benefits and Drawbacks?,", DIT article in press, 2022.

[28] S. Fleury, E. Jamet, E. Loup-Escande, A. Ghorbel, A. Lemaitre \& E. Anquetil, "Towards Specifications for Automatic Recognition Software: An Example of a User-Centred Design," Journal of Software Engineering and Applications, 6, 1, 2013.

[29] D. A. Norman, "The psychology of everyday things," Basic books, (1988).

[30] M. van der Bijl-Brouwer, "The challenges of human-centred design in a public sector innovation context". In Proceedings of 2016 Design Research Society 50th Anniversary Conference, 27-30 June, 2016.

[31] Moody, L. (2015). User-centred health design: reflections on D4D's experiences and challenges. Journal of Medical Engineering \& Technology, 39(7), 395-403.

[32] M. I. Hi Chun, C. Harty, \& L. Schweber, "Comparative study of usercentred design approaches". In Proceedings of the 31st Annual ARCOM Conference, pp. 7-9, 2015

[33] M. Thinyane, K. Bhat, L. Goldkind, \& V. K. Cannanure, "Critical participatory design: reflections on engagement and empowerment in a case of a community-based organization," In Proceedings of the 15th Participatory Design Conference: Full Papers-V1 pp. 1-10, 2018

[34] Survey Web Site :

[35] M. Topolewski, P. Krawczyk, M. Pallot and J. Huotari, "Applying, a In the Proceedings of the 26th IEEE Int'l Conference on Engineering, Technology and Innovation, 2020.

[36] ISO FDIS 9241-210, "Ergonomics of human-system interaction - Part 210: Human-centered design for interactive systems (formerly known as 13407)," 2009.

[37] E. L.-C. Law, V. Roto, M. Hassenzahl, A. P. O. S. Vermeeren, and J. Kort, "Understanding, scoping and defining user experience," Proc. 27th Int. Conf. Hum. factors Comput. Syst. - CHI 09, no. April 2016, p. 719,2009 .

[38] K. Tcha-Tokey, O. Christmann, E. Loup-Escande, G. Loup, S. Environments," Advances in Human-Computer Interaction, vol. 2018.

[39] A. McMahan, "Immersion, engagement and presence," in The Video Game Theory Reader, D. M. J. Wolf and B. Perron, Eds., pp. 67-86, 2003

[40] A. I. Nordin, J. Ali, A. Animashaun, J. Asch, J. Adams, and P. Cairns, "Attention, time perception and immersion in games," in CHI '13 Extended Abstracts on Human Factors in Computing Systems on - CHI EA'13, 2013, pp. 1089-1094.

[41] M. Pallot, and S. Richir, "Laval Virtual Vision 2025: Blurring the lines between digital and physical worlds," In Proceedings of the 11 th Intl Conf. Disability, VR \& Associated Technologies, pp. 1-9, 2016.

[42] E. Adams, "Postmodernism and the Three Types of Immersion". Gamasutra. Designersnotebook.com, July 9, 2004.

[43] B. Staffan \& J. Holopainen, "Patterns In Game Design," Charles River Media. p. 206. ISBN 1-58450-354-8. 2004

[44] W. Wirth, T. Hartmann, S. Böcking, P. Vorderer, C. Klimmt, H. presence experiences," Media Psychology, 9, 493-525, 2007.

[45] J.J. Cummings, J.N. Bailenson, "How immersive is enough? A metaanalysis of the effect of immersive technology on user presence," Media Psychology. 1-38, 2015.

[46] G. Gooskens, "Immersion," In the Proceedings of the European Society for Aesthetics, vol. 6, 2014.

[47] A. Heydarian, J. P. Carneiro, D. Gerber, B. Becerik-Gerber, "Immersive virtual environments, understanding the impact of design features and occupant choice upon lighting for building performance," Building and Environment. 89: 217-228, 2015.

[48] K. Chamilothori, J. Wienold, M. Andersen, "Daylight patterns as a means to influence the spatial ambiance: a preliminary study," In the Proceedings of the 3rd International Congress on Ambiances, 2016.

[49] O. Broberg, V. Andersen, \& R. Seim, "Participatory ergonomics in design processes: The role of boundary objects," Applied ergonomics, 42(3), 464-472, 2011.

[50] S. Kalantari, \& J. R. J. Neo, "Virtual Environments for Design Research: Lessons Learned from Use of Fully Immersive Virtual Reality in Interior Design Research". Journal of Interior Design, 2020.

[51] Z. Zhang, \& W. Pan, "Virtual Reality Supported Site Layout Planning for Modular Integrated Construction of High-Rise Buildings". In Construction Research Congress 2020: Project Management and Controls, Materials, and Contracts (pp. 339-347). Reston, VA: American Society of Civil Engineers, 2020.

[52] M. F. Shiratuddin, W. Thabet, \& D. Bowman, "Evaluating the effectiveness of virtual environment displays for reviewing construction 3D models," CONVR 2004, 87-98, 2004

[53] M. Tavanti, \& M. Lind, "2D vs 3D, implications on spatial memory". In IEEE Symposium on Information Visualization, 2001. INFOVIS, pp. 139-145, 2001.

[54] H. Levene, "Robust tests for equality of variances". In Ingram Statistics: Essays in Honor of Harold Hotelling. Stanford University Press. pp. 278-292, 1960

[55] K. Pearson, "On the criterion that a given system of deviations from the probable in the case of a correlated system of variables is such that it can be reasonably supposed to have arisen from random sampling," Philosophical Magazine. Series 5. 50 (302): 157-175, 1990 